\title{
ASSESSMENT OF THE RELATION OF THE OPTIC NERVE TO THE POSTERIOR ETHMOID AND SPHENOID SINUSES BY COMPUTED TOMOGRAPHY
}

\author{
Gabriela Heskova $^{\text {a*}}$, Yvetta Mellova ${ }^{a}$, Anna Holomanova ${ }^{\mathrm{b}}$, Desanka Vybohova ${ }^{\mathrm{a}}$, \\ Lenka Kunertova ${ }^{\mathrm{a}}$, Magdalena Marcekova ${ }^{\mathrm{a}}$, Milan Mello ${ }^{\mathrm{a}}$
}

\author{
a Jessenius Faculty of Medicine in Martin, Institute of Anatomy, Comenius University in Bratislava \\ ${ }^{b}$ Faculty of Medicine, Institute of Anatomy, Comenius University in Bratislava, Mala Hora STR. N. 4, 03754 Martin, \\ Slovakia \\ e-mail:heskova@lefa.sk
}

Received: September 10, 2008; Accepted: December 12, 2008

Key words: Optic nerve/Sphenoid sinuses/Posterior ethmoid sinuses/Computed tomography

Objective: The aim of this study was to observe the relationship of the sphenoid sinus and posterior ethmoid cells with the optic nerve.

Material and Methods: 34 CT scans (68 sides) of paranasal sinuses of patients older than 18 years were retrospectively reviewed. Images were assessed in two planes - axial and coronal. We observed the position and relationship of the optic nerve to the posterior ethmoid and sphenoid sinuses, bony dehiscence and protrusion of the optic nerve into sinuses, and pneumatization of the anterior clinoid process.

Results: The most frequent position of optic nerve $(\mathrm{ON})$ was a location close to the posterior ethmoid and sphenoid sinuses without contacting or indentation of the wall - $55.9 \%$ (38 nerves). The bulging of ON to sphenoid sinus was found in $14.7 \%$ ( 10 nerves) and the course of the nerve through sinus in 16 nerves $(23.5 \%)$. The position of ON intimately to both sinuses was observed in $5.9 \%$ (4 nerves). Protrusion of ON, dehiscence of the bony wall and pneumatization of anterior clinoid process (ACP) was seen in 12 (35.3\%), 4 (11.8\%) and 9 (26.5\%) patients, respectively. Both the protrusion of $\mathrm{ON}$ and ACP pneumatization were present in $8(23.5 \%)$ patients on the right side and in $5(14.7 \%)$ patients on the left side.

Conclusion: Variations of posterior ethmoid and sphenoid sinuses are numerous and may entail potential risk of injury of the $\mathrm{ON}$ during sinus surgery. Knowledge of individual differences and configurations in the operation area may help the surgeon to prevent complications. Computed tomography is the preferred radiographic modality for evaluation of bony variations and the pathology of this region.

\section{INTRODUCTION}

The optic nerve $(\mathrm{ON})$ has an intimate relationship to the posterior ethmoid cells and sphenoid sinus. The position of $\mathrm{ON}$ may be changed due to various degrees of pneumatization of the sinuses and it may produce a bulge into them that is scarcely visible or clear. Pneumatization of the sphenoid sinus (SS) can be so extensive that it can even surround the anterior clinoid process (ACP), $\mathrm{ON}$, foramen rotundum, vidian canal, pterygoid process, or maxilloethmoid process ${ }^{1}$. A surgically dangerous area is pneumatization of posterior ethmoid cells behind the annulus tendineus communis where the optic nerve is unprotected by surrounding extraocular muscles, fatty tissue and periorbita ${ }^{2}$. Extensive pneumatization may predispose to optic nerve injury.

Detailed knowledge of paranasal sinuses and adjacent anatomical structures notably their variations are essential for clinicians performing sinus surgery. This is important to know preoperatively, so that unintentional damage to these structures can be avoided.

\section{MATERIAL AND METHODS}

Computed tomography (CT) study was reevaluated retrospectively. $34 \mathrm{CT}$ scans (68 sides) of paranasal sinuses of patients older than 18 years were investigated. The age range was 18 to 74 years (mean age 45 years). There were 17 females and 17 males.

Patients were scanned on Somatom Sensation 10 (Siemens, Germany) and on Philips Brilliance 2 according to these parameters: slice thickness - $1 \mathrm{~mm}$, increment $-1 \mathrm{~mm}, 120 \mathrm{kV}, 150 \mathrm{mAs}$, window bone (center $800 \mathrm{HU}$, width $2000 \mathrm{HU}$ ). Data was acquired on the axial plane and coronal plane was created by secondary reconstruction method. Images were assessed in both planes - axial and coronal. Coronal CT scans were preferred for the detection of protrusion of the $\mathrm{ON}$ into sphenoid sinus, while axial scans are better for details of the complete course of the optic nerve to sphenoid and ethmoid sinuses.

The relations of the optic nerve to sphenoid and ethmoid sinuses were assessed according to DeLano et al. (1996) and were classified into four different types (assessed in axial plane): 
- in type 1 , the nerve does not contact or impinge on either the sphenoid or posterior ethmoid cells

- in type 2, the nerve indents the sphenoid sinus, without contacting the posterior ethmoid cells (PEC)

- in type 3, the nerve runs through the sphenoid sinus, and it is surrounded by the pneumatized sinus for at least $50 \%$

- in type 4, the nerve courses close to both the sphenoid sinus and posterior ethmoid sinus.

Protrusion of optic nerve and bony dehiscence of the wall of optic nerve was evaluated according to the criteria of Sirikci et al. ${ }^{1}$ and Ünal et al. ${ }^{4}$. In coronal section, protrusion was defined as the presence of more than half the circumference of the concerned structures into the sinus cavity with or without defects in their bony margins. Bony dehiscence was determined as the absence of visible bone density separating the sinus from the course of the optic nerve. Protrusion of ON may coexist with ipsilateral pneumatization of anterior clinoid process or migration of the posterior ethmoid air cells posteriorly into the upper sphenoid - sphenoethmoidal or Onodi cells ${ }^{1}$. Onodi cells were not assessed in our study.

CT scans were examined by two independent observers. The results were classified as present or absent variation. CT scans which were non-consensually evaluated were excluded from our study.

\section{RESULTS}

Position of the optic nerve to ethmoid and sphenoid sinuses was divided into four categories according to
Table 1. Incidence of optic nerve (ON) into four types by the relation to posterior ethmoid and sphenoid sinuses according to DeLano et al. (1996).

\begin{tabular}{|c|c|c|}
\hline & Number of ON & \% \\
\hline Type 1 & 38 & 55.9 \\
\hline Type 2 & 10 & 14.7 \\
\hline Type 3 & 16 & 23.5 \\
\hline Type 4 & 4 & 5.9 \\
\hline
\end{tabular}

DeLano et al. ${ }^{3}$ : type 1 with a proportion of $55.9 \%$ (38 nerves), type 2 was detected in $14.7 \%$ (10 nerves) of the cases, type 3 - was identified in $23.5 \%$ (16 nerves) and type 4 in $5.9 \%$ ( 4 nerves). Table 1 . shows the division of the $\mathrm{ON}$ into four types according to the relation to posterior ethmoid and sphenoid sinuses.

The protrusion of the ON was assessed in 12 (35.3\%) patients. Protrusions were right sided, left sided and bilateral in $3(8.8 \%), 3(8.8 \%)$, and $6(17.7 \%)$ sides, respectively. Dehiscence of the bony wall of the $\mathrm{ON}$ was found in $4(11.7 \%)$ patients of which $1(2.9 \%)$ was right sided and $3(8.8 \%)$ were left sided.

Pneumatization of the anterior clinoid process was seen in $9(26.5 \%)$ patients. This was on the right side in $4(11.8 \%)$, on the left side in $1(2.9 \%)$ and bilateral in $4(11.8 \%)$. The concomitant presence of the ON protrusion and ACP pneumatization was observed in $8(23.5 \%)$ patients on the right side and in $5(14.7 \%)$ patients on

Table 2. The prevalence of the protrusion of the optic nerve, dehiscence of the bony wall and pneumatization of anterior clinoid process (ACP).

\begin{tabular}{|l|c|c|c|c|}
\hline & Right side & Left side & Bilateral & Total \\
\hline Protrusion of ON & $3(8.8 \%)$ & $3(8.8 \%)$ & $6(17.7 \%)$ & $12(35.3 \%)$ \\
\hline Dehiscence & $1(2.9 \%)$ & $3(8.8 \%)$ & 0 & $4(11.7 \%)$ \\
\hline Pneumatization of ACP & $4(11.8 \%)$ & $1(2.9 \%)$ & $4(11.8 \%)$ & $9(26.5 \%)$ \\
\hline
\end{tabular}

Table 3. Review of results of optic nerve $(\mathrm{ON})$ protrusion, dehiscence of bony wall and pneumatization of anterior clinoid process (ACP).

\begin{tabular}{|l|c|c|c|}
\hline & $\begin{array}{c}\text { Protrusion } \\
\text { of ON }\end{array}$ & $\begin{array}{c}\text { Dehiscence of bony wall } \\
\text { of the ON }\end{array}$ & $\begin{array}{c}\text { Pneumatization } \\
\text { of ACP }\end{array}$ \\
\hline Sirikci et al. & $31.5 \%$ & $22.8 \%$ & $29.3 \%$ \\
\hline DeLano et al. & unrefered & $24 \%$ & unrefered \\
\hline Ünal et al. & $31.3 \%$ & $16.9 \%$ & $24.1 \%$ \\
\hline Bademci et al. & $34.4 \%$ & $7.7 \%$ & unrefered \\
\hline Sapci et al. & unrefered & $13.5 \%$ & $11 \%$ \\
\hline Hewaidi et al. & $35.6 \%$ & $30.6 \%$ & $15.3 \%$ \\
\hline
\end{tabular}




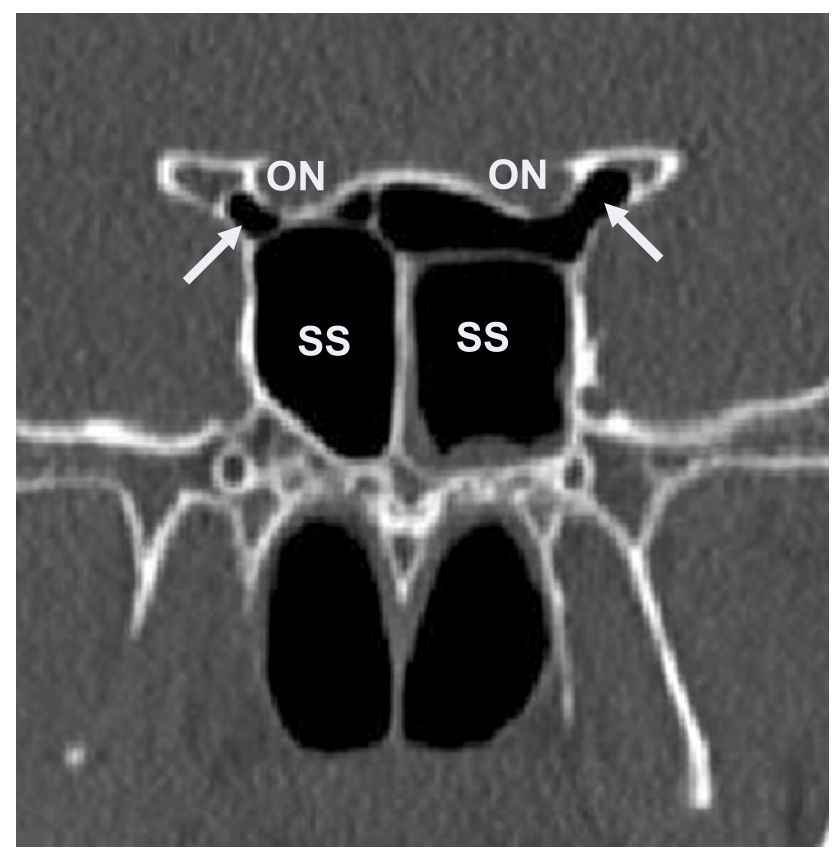

Fig. 1. Coronal CT image showing bilateral pneumatization of anterior clinoid processes (arrow) and bilateral protrusion of optic nerves $(\mathrm{ON})$ in sphenoid sinus (SS).

the left side. Table 2. shows the prevalence of ON protrusion, dehiscence of the bony wall and pneumatization of ACP.

\section{DISCUSSION}

Several anatomic variations of the ethmoid and sphenoid sinuses increase the risk for injury of adjacent structures during endoscopic sinus surgery. Inadvertent injury to these structures can result in uncontrollable bleeding, retrobulbar hematoma with acute proptosis, diplopia caused by extraocular muscle injury and stretching of the optic nerve resulting in blindness, violation of the subarachnoid space with resultant pneumocephalus or cerebrospinal fluid rhinorrhea ${ }^{2,5}$. Damage of the optic nerve is serious complication of intranasal sinus surgery. Protrusion of the optic canal into the sphenoid and/or ethmoid sinuses has considerable clinical importance.

In the present study, we found $38.2 \%$ nerves in the second and the third categories which are regarded the most critical for the potential risk of injury of ON.

DeLano et $\mathrm{al}^{3}{ }^{3}$ reviewed $150 \mathrm{CT}$ scans - 300 nerves, which all were intimately related to the sphenoid sinus. Only $3 \%$ were in contact with the posterior ethmoid cells (PEC). They reported - type 1 - $76 \%$, type $2-15 \%$, type $3-6 \%$ and type $4-3 \%$. Sapci et al. (2004) observed type $1-64 \%$, type $2-22 \%$, type 3 and 4 are both $7 \%$ of the total number. They reviewed $100 \mathrm{CT}$ scans. Li et al. ${ }^{7}$ found whole optic canals neighboured with PEC, SS and both in $39 \%, 43 \%$ and $18 \%$ of cases, respectively. They reported the bulgings of optic canal into the lateral wall



Fig. 2. Coronal CT image showing bilateral pneumatization of anterior clinoid processes (arrow), protrusion of right optic nerve $(\mathrm{ON})$ in sphenoid sinus (SS) and dehiscence (arrowhead) of the bony wall of $\mathrm{ON}$ on the right side.

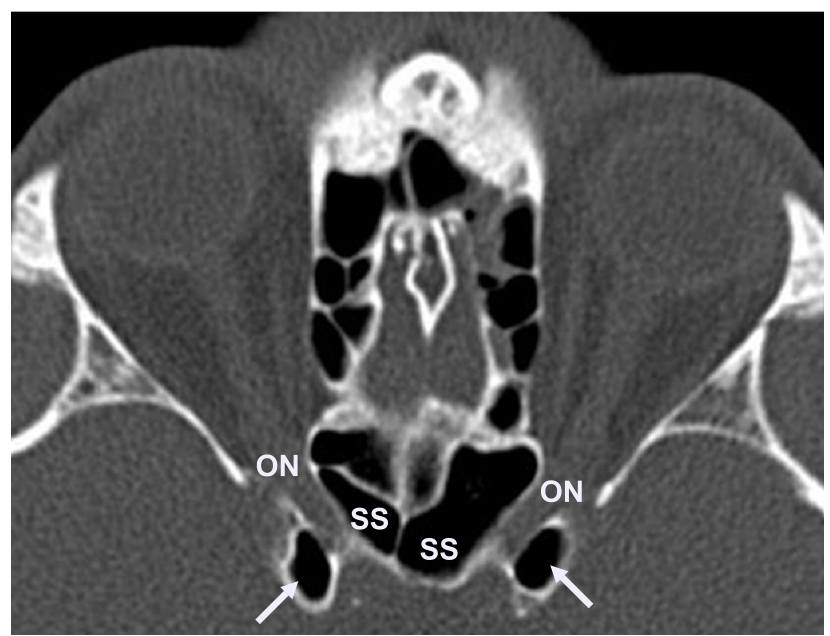

Fig. 3. Axial CT image showing bilateral pneumatization of the anterior clinoid processes (arrow) and bilateral optic nerves (ON) inside sphenoid sinus (SS).

of PEC and SS in $48 \%$ and $47 \%$ of cases, respectively. Markalous et al. ${ }^{2}$ described the intimate relations of $\mathrm{ON}$ to posterior ethmoid cells in $65 \%$ cases.

The incidence of the protrusion of the ON, dehiscence of the bony wall of the ON and pneumatization of ACP has been well discussed in the literature. Table 3. shows a review of the results.

Pneumatization of anterior clinoid process forms the opticocarotid recess, i.e. the small space on the lateral wall of the sphenoid sinus, between the optic canal, supe- 
riorly, and the carotid prominence, inferiorly. The opticocarotid recess is presumed to concur with ipsilateral optic nerve protrusion into the sphenoid sinus 8 .

Sirikci et al. ${ }^{1}$, Ünal et al. ${ }^{4}$ and Hewaidi et al. ${ }^{8}$ reported a significant relationship between protrusion of the $\mathrm{ON}$ into SS and the pneumatization of ACP. We observed $23.5 \%$ patients on the right side and $14.7 \%$ patients on the left side with both pneumatization of ACP and protrusion of $\mathrm{ON}$.

\section{CONCLUSIONS}

The indentation, protrusion or the course of optic nerve through the sphenoid sinus, bone dehiscence over the nerve and pneumatization of the anterior clinoid process are anatomic configurations that predispose to optic nerve injury during surgical intervention in this region $^{3}$. Our results show that named anatomical configurations are frequent, confirm findings of more authors and support the opinion that CT examination is an ideal method for the detection of the bony variations of paranasal sinuses. Axial and coronal scans are necessary images for visualisation of the position of the optic nerve. It is essential in preoperative planning to ensure the safety and efficiency of paranasal sinus surgery.

\section{REFERENCES}

1. Sirikci A, Bayazit YA, Bayram M, Mumbuc S, Güngör K, Kanhkama M. Variations of sphenoid and related structures. Eur. Radiol. 2000; 10: 844-848.

2. Markalous B, Charvát $\mathrm{F}$ et al. Chirurgicky nebezpečné oblasti rinobaze. IN: Zobrazení hlavy, paranazálni dutiny, lební baze a obličejová část. Praha Maxdorf 2000; 104-108.

3. DeLano MC, Fun FY, Zinreich SJ. Relationship of the optic nerve to the posterior paranasal sinuses: a CT anatomic study. AJNR Am J Neuroradiol. 1996; 17( 4 ): 669-75.

4. Ünal B, Bademci G, Bilgili YK, Batay F, Avci E. Risky anatomic variations of sphenoid sinus for surgery. Surg Radiol Anat 2006; 28: 195-201.

5. Bademci G, Ünal B. Surgical Importance of Neurovascular Relationships of Paranasal Sinus Region. Turkish Neurosurgery, 2005; Vol.: 15, No: 2: 93-96.

6. Sapci T, Derin E, Almac S, Cumali R, Saydam B, Karavus M. The relationship between the sphenoid and the posterior ethmoid sinuses and the optic nerves in Turkish patients. Rhinology, 2004; Mar. 42 (1): 30-4.

7. Li Y, Xu G, Yang Y. Anatomical relationship of the ethmoidsphenoid areas to the optic canal and the internal carotid artery. Zhonghua Er Bi Yan Hou Ke Za Zhi, 1995; 30 (2): 87-89.

8. Hewaidi GH, Omami GM. Anatomic Variation of Sphenoid sinus and Related Structures in Libyan population: CT Scan Study. Libyan J Med, 2008; AOP: 080307, Vol. 3, No.: 3: 128-133. 